\title{
Relevance Analysis of Second Language Acquisition and College English Teaching
}

\section{Du Xuan}

\author{
Nanping Branch, Fujian Radio Broadcasting TV University, Nanping, Fujian, 353000
}

Keywords: second language acquisition, English teaching in colleges and universities, relevance analysis

\begin{abstract}
There are many differences between Chinese and English countries. All of these differences make it difficult for L2 learners to keep up with the pace of learning and thus have a significant impact on English teaching in colleges and universities. Therefore, this paper will mainly focus on the related theoretical knowledge and characteristics of second language acquisition, analyze the impact of the second language acquisition idioms on English teaching in colleges and universities and its important role. Combined with practical experience, this paper will explore how the second theoretical knowledge of language acquisition is applied to the actual English teaching to promote the development of their education quality while promoting the improvement of students' thinking and learning ability.
\end{abstract}

\section{Connotation and Characteristics of Second Language Acquisition}

\subsection{Connotation of Second Language Acquisition}

Second language, as its name implies, is the second type of foreign language learning that occurs in addition to its own native language. We can simply understand second language acquisition as a study of theories related to other language learning beyond our own. In fact, the theoretical knowledge of second language acquisition is very abstract and complicated, which mainly includes "innate theory of second language acquisition", "second language acquisition environment theory" and "Second Language Acquisition Interaction Theory." These three kinds of theoretical knowledge study, from different aspects, students' learning of second language and related cognition. According to the innate theory of second language acquisition, we can conclude that this theory mainly assumes that the ability to learn the language is inherent to the students, rather than acquired through environment and other factors. This theory emphasizes the effect of brain mechanism on students' learning of second language. It is believed that students' language learning mainly depends on the learning mechanism in the brain that helps students to learn second language. Second language acquisition environment theory as its name suggests that students' language learning ability is influenced by the surrounding environment, and students' language learning ability is largely affected by the surrounding environment. It also indicates that students also need the ability to overcome these challenges to be able to better engage in second language learning. Second Language Acquisition and Interaction Theory is that second language learners in the process of learning are influenced by both internal conditions and environmental factors. Influencing by these two factors, it requires learners to find ways to integrate their internal conditions with the environment around them in order to promote their own learning development.

\subsection{The Main Features of Idioms in Second Language Acquisition}

In according to the analysis of experts, the idioms in English are usually divide into two types from the narrow sense and broad sense.

Broadly speaking, idioms refer to all idiomatic and special expressions in a national language, including fixed phrases, proverbs, phrases, slang, aphorisms, mottos, various idiomatic expressions and so on. While in a narrow sense, during the long-term development of the language, idioms with different literal and liberal meaning only refer to the fixed phrases which can be applied to express 
the complete meaning. As a type of common or customary special language, idioms with relatively fixed syntactic, lexical or phonetic forms, refer to the phrases or clauses which can be used as single units in semantic and discourse function. But in the second language acquisition process, we can clearly understand that English idioms are semantic complete and structurally fixed whether analyzing the main features of idioms from a narrow sense or in a broad sense. We can understand it through an idiom. By using an idiom we can understand what it means and it fits perfectly with the structure of the English language.

\section{The Promotion of College English Teaching by Idioms in Second Language Acquisition}

The number of idioms in English is very large. After a long period of development and wide application, a distinctive idiom system has been eventually formed. English idioms have an important role in English Teaching. They are simple in form and some of them contain unique culture of English-speaking countries, which can bring a beautiful enjoyment to second language learners. As a result, language learners can better understand the culture of English and deepen understanding of the second language.

\subsection{English Idioms Enable Second Language Learners Understand Anglo-American Culture and Lay a Solid Foundation}

Second language learning is rather difficult for many people. The main reason is that second language learners do not understand Anglo-American culture and do not understand what they are learning. By combining English idioms in second language acquisition with English teaching in colleges and universities in our country, students can learn more about the culture of Anglo-American countries while they learn English and improve their cultural level. To improve the interest of learning in the study of English, the theoretical knowledge of two language acquisition can really promote the development of its own.

\subsection{Help Students to Understand More Words as Well as Self Improvement}

There are many English idioms that have double meaning, which makes students effectively expand their knowledge and vocabulary when they come into contact with English idioms. It's a better way for English learners to enlarge their vocabulary than to dictate dictionaries. For English majors, the competition they are facing makes English teaching in colleges and universities must improve their ability in many aspects. Through the teaching of idiom in second language acquisition, students in colleges and universities can learn more, which will qualitatively make college English teaching achieve some results, and can also improve the English majors' ability.

\section{The Teaching Method of English Idioms under the Guidance of Second Language Acquisition Theory}

The greatest problem encountered in English teaching in our country is that students are influenced by their own native language in the process of learning. They always adopt the traditional Chinese thinking mode and cannot change their ways of thinking from their mother tongue to the second language which leads to a big challenge to English teaching in our country. On the other hand, the lack of teachers in our country also makes the ability of many teachers in colleges and universities very limited. Many teachers do not do enough work to guide the students' logical thinking ability in the actual teaching process, which makes the students encounter great difficulties in English learning process. In order to make further breakthroughs in English teaching in our country, teachers should pay attention to two points in practical English teaching. One is to pay attention the cultivation of English language thinking ability and the other is to strengthen the study of idiom recognition.

\subsection{Emphasis on Cultivating English Linguistic Thinking}

Due to the influence from their mother tongue in the learning process, most second language 
learners would learn the English language habitually with Chinese thinking pattern. They use Chinese to describe English vocabulary or sentences and then adopt loan translation or transliteration, which is how the so-called "Chinglish" comes into being. Therefore, teachers should focus on the implantation and order of language thinking and create a second language using environment for students in the process of creating the second language acquisition environment. They should also unify the teaching and learning, stimulate students' enthusiasm to participate in every step of language input decoding- semantic construction - recoding - language output, and ultimately achieve the desired learning results and the communicative goal of English teaching.

\subsection{Reinforce the Study of Idiom Recognition}

English idioms are broad and profound, including lots of cultural knowledge, of which the most important is the use of rhetorical devices. Therefore, teachers should analyze specific cases in College English teaching and adoptvariousteaching approaches according to different rhetorical methods. While consolidating the theoretical basis in teaching practice, teachers should also attach importance to the idiom recognition teaching, strengthen the idiom memory, and guide students to understand and notice the cultural background and real life of English-speaking countries.

\section{Conclusions}

With the continuous improvement of China's comprehensive national strength, a large number of foreign language talents are needed in the market of our country. Therefore, the education industry in our country constantly increases the training of English talents and the study of second language acquisition. Second language acquisition theory belongs to the part of ideology. Various colleges and universities in English teaching how to effectively use second language acquisition into their own practical teaching to become the main purpose of a major university research on second language acquisition. However, due to the immature theory of second language acquisition in our country and the defects in many aspects, the research on second language acquisition has also become one of the difficulties in college English teaching. In the process of actual English teaching, we found that the mother tongue has an important influence on the students who learn the second language, which can directly affect the learning effect of the students. This is mainly because there are many cultural differences, historical differences, religious beliefs and lifestyle differences between the English-speaking countries and China. The current need of foreign language talents in our country urges colleges and universities in our country to strengthen their own English teaching and improve their teaching abilities through studying the second language acquisition. Especially for idioms, there is a huge difference between China and Britain, because these idioms and expressions represent a country's culture. Therefore, considering the relevance between second language acquisition and college English teaching, when studying the theoretical knowledge of second language acquisition, our teachers engaged in college English teaching should further study, make full use of the role of theoretical knowledge of second language acquisition, try their best to improve the quality of college English teaching and the efficiency of learning second language.

\section{References}

[1] Wu Xudong. The Influence of Idioms Type and L2 Levels on the Use of Idioms Comprehension Strategies [J]. Modern Foreign Language, 2014, (1):62-73.

[2] Zeng Tao, Zhou Jie, Liu Rongfeng etc. The Effects of Contextual Effects, Second Language Proficiency and Degree of Difficulty on Chinese College Students' English Idioms Learning [J]. English Teachers, 2014, (8):32-38. 